\title{
The Post-Program Era
}

\section{The Rise of Internet \& Society Centers - and a New Interdiscipline}

\author{
Jefferson Pooley, Muhlenberg College \\ pooley@muhlenberg.edu
}

March 5, 2018

This article was original published as Jefferson Pooley, "The Post-Program Era: The Rise of Internet \& Society Centers - and a New Interdiscipline,” Culture Digitally, March 5, 2018, http:// culturedigitally.org/2018/03/the-post-program-era-the-rise-of-internet-society-centers-and-a- 


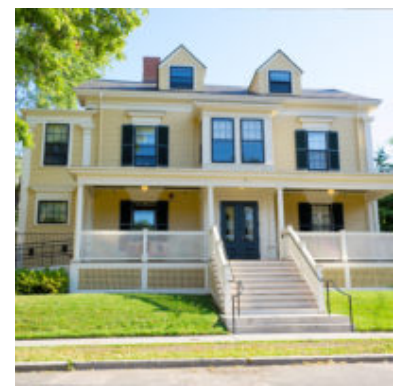

\section{The Post-Program Era:} The Rise of Internet \& Society Centers-and a New Interdiscipline

JEFF POOLEY · MARCH 5, 2018

If you're into media and tech issues, tomorrow could be busy: Harvard's Berkman Klein Center is hosting a talk on algorithms in policing. Later in the day, if you're in New York, you could attend a Cornell Tech session on digital safety for domestic violence victims-the latest installment of the new campus's Digital Life Seminar. Perhaps you're in Toronto, in which case you'd want to catch the McLuhan Centre's conference on worker resistance in the platform economy. Or Seattle: the University of Washington's Tech Policy Lab has a lecture by Microsoft Research's Kate Crawford on Al that night. Another option, since most of these events are streamed live, would be the Oxford Internet Institute's seminar on social media warfare.

You could always tune in, Wednesday, to the Internet Institute's Oxford neighbor, the Reuters Institute for the Study of Journalism, for a talk on political fact-checking. Or there's Yale's Information Society Project, which is hosting a workshop Friday on cross-border data transfers. It's a bit of a wait-the event is in a week-but you might hold your calendar for a lecture on algorithmic uncertainty at the Humboldt Institut für Internet und Gesellschaft in Berlin.

That's a lot to take in over a single week. And the following week is packed too, with events at these and peer institutes across the world. You could, if you had the time, binge on streams and
With support from:

The National Science Foundation, Temple University, and Cornell University

\section{TRAFFIC}

THROTTLING?

SITE BLOCKING?

NEW FEES?

NO THANKS.

\section{SAVE}

NET NEUTRALITY.

\#CULTD

Tweets about "\#cultd"

FOUNDERS

Tarleton Gillespie

Hector Postigo

Josh Braun

Sam Srauy 
podcasts-and reports and infographics-from these nowubiquitous research centers.

None of them existed 25 years ago.

There's a new academic meta-field, centered on digital life, that doesn't look anything like a traditional discipline. The field is more like an estuary, fed by a number of existing disciplineslibrary and information science, law, sociology, science and technology studies, and communication. It's an interdisciplinary mashup of fields whose domains ("media", "information," "technology") have merged.

There's nothing surprising about the intellectual momentum: rapid social change always calls attention to itself. Ambitious scholars mix with curious benefactors, writers trade alarmist and upbeat takes, and initiatives get launched. The modern social sciences, in the U.S. at least, emerged as a sense-making response to late 19th-century social churn. A society on the move is always throwing its novelty into relief; yesterday's order makes today feel weird. So we would expect the last two decades of unending digital upheavel to generate an academic echo.

What makes the new, nameless formation interesting is its place in the university: the new field is seeded by institutes thatcrucially-exist outside the established department system. It is a resolutely cross-disciplinary field, whose brick-and-mortar centers, like Harvard's Berkman Klein Center for Internet \& Society, are designed for idea exchange. The academics who populate the field, they reside in established departments and schools; it's when they have thinking to share that they travel to Cambridge or to one of the other institutes.

So what's formed over the last two decades is an extradepartmental crossroads. Lightly staffed centers, with few standing faculty, welcome a rotating cast of visiting speakers and affiliated fellows. Sharply designed, public-facing reports, perhaps open source tools and a podcast series-these are the centers' main outputs.
AUTHORS

Adam Fish

Adrienne Shaw

Alice Marwick

Alison Harvey

Andrés Monroy-Hernández

Anne Helmond

Annette markham

Alison Novack

Aphra Kerr

Arturo Arriagada

Aynne Kokas

Ben Peters

Elizabeth Wissinger

Brooke Erin Duffy

Burcu S. Bakioglu

C.W. Anderson

Carla Ilten

Carrie Rentschler

Casey O'Donnell

Christina Dunbar-Hester

Christopher Boulton

Chuck Tryon

Dan Greene

Daniel Kreiss

Daren Brabham

Dawn Nafus

Daniel Guagnin

Eugenia Mitchelstein

Fenwick McKelvey

Finn Brunton

Fred Turner

Gabriella Coleman

Gina Neff

Greg Lastowka

Graham Meikle

Guobin Yang

Hope Forsyth

Hugh Gusterson

Ilana Gershon

Jan Fernback

James Bennett

Jean Burgess

John Carter McKnight

Jeff Drouin

Jennifer Lena

Jessa Lingel

Jesse Houf

Jessica Beyer

Joan Donovan

Joe Turow 
The new digital-studies institutes have flourished at elite universities-like Harvard and Oxford-that could never really stomach the idea of training journalists or librarians.

Communication research and library science were sneered at for their vocational grubbiness. Berkman and the Oxford Internet Institute are, in that sense, an institutional end-run around the student-supported disciplines that employ the bulk of their visitors and fellows.

The centers' free-floating quality-their unabashed detachment from the department system and its undergraduate underwriters-makes them both exciting and unstable.

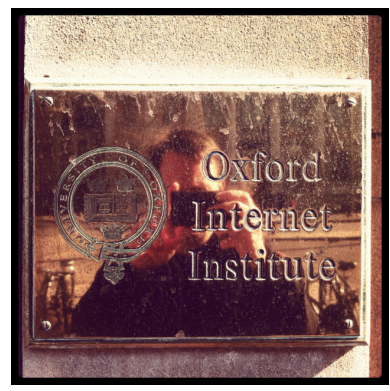

It was the collision of existing U.S. law and new communication technologies that jump-started the new meta-field. For some time, the American legal system hadn't kept pace with changes in the telecommunications and media industries. But the chasm opened by the World Wide Web's early 1990s

debut was the decisive development: Whole areas of law needed to be rethought in the popular Internet's wake. Law school faculty were primed to think about these problems, of course. But they took up the challenge with a cross-disciplinary gusto that must have startled their social science colleagues across campus. In fact, law school faculty, especially at the elite schools and with gathering force since the 1970s, had come to think of themselves less as practitioner-educators than as university professors. And the kind of professor they had become, by the mid-1990s, was peculiar: Elite law school faculty, many of them anyway, were now specialists in interdisciplinarity, with a shared conviction that law shouldn't be studied in isolation. The result was that the best-read-the most intellectually nimble-social scientists on campus had no Ph.D. And the ones with an interest in media and technology did what modern law professors do: They established centers devoted to the topic.

UC Berkeley's Center for Law \& Technology was the first such law-school affiliated center, founded in 1995. Yale's Information

\author{
John Banks \\ John Durham Peters \\ John Sullivan \\ Jonathan Sterne \\ Joshua McVeigh-Schultz \\ Jeff Pooley \\ Julia Sonnevend \\ Karin Wahl-Jorgensen \\ Karine Nahon \\ Kate Zyskowski \\ Katherine D. Harris \\ Katy Pearce \\ Kevin Driscoll \\ Kate Miltner \\ Laura Forlano \\ Lee Humphreys \\ Lee Vinsel \\ Limor Shifman \\ Lisa Nakamura \\ Lonny J Avi Brooks \\ Lisa Silvestri \\ Lucas Graves \\ Mack Hagood \\ Mari Castaneda \\ Mark Chen \\ Mark Deuze \\ Mary Gray \\ Matthew Crain \\ Matt Ratto \\ Mél Hogan \\ Mel Stanfill \\ Mélanie Millette \\ Mike Ananny \\ Neal Thomas \\ Nicholas John \\ Nick Couldry \\ Niels van Doorn \\ Natalie Stroud \\ Niki Strange \\ Paul Hillier \\ Pablo Boczkowski \\ Patrick Vonderau \\ Phil Howard \\ Rasmus Nielsen \\ Ray Fouche \\ Rena Bivens \\ Ryan Milner \\ Robert Gehl \\ Rodrigo Zamith \\ Rosemary Avance \\ Samuel Woolley \\ Sara Kingsley \\ Sarah Banet-Weiser \\ Saugata Bhaduri
}


Society Project was started in 1997, the same year as Berkman. But it was the Berkman example that made the law school a locus of internet studies in the millienium's first decade. Early figures like Jonathan Zittrain, a co-founder, and Lawrence Lessig, the first Berkman Professor, introduced a wide remit for the Center, with an interventionist ethos: the "best way to understand cyberspace," the Center declared, "is to actually build out into it." Two years after Berkman's founding, an already-prominent Lessig left Harvard for Stanford Law School, where he established the Center for Internet and Society in Berkman's mold. Similar institutes at NYU, Michigan State, and the University of Ottawa soon followed.

Inspired by Berkman but untethered to a law school, Oxford established its own Internet Institute in 2001. Five years later, Oxford's center (which is technically a department) began offering a doctoral degree in "Information, Communication and the Social Sciences." Then, in 2008, Berkman itself was recast as a university-wide initiative. After a century of indifference, the academic study of media finally had a home at Harvard.

By 2012, the now far-flung community of institutes established an umbrella group, the Network of Internet \& Society Centers. The Network's 60-odd member-centers represent 34 countries across five continents, though with striking disparities: More than half the institutes are based in Europe, while only a single center, the University of Cape Town's Research ICT Africa, is in sub-Saharan Africa.

The latest member of the "internet and society" club is the Weizenbaum Institute for the Networked Society, which launched late last year with a five-year, €50 million commitment from the German government. The Berlin-based center was jointly proposed by seven higher-ed institutions in and around the city, and won out over bids from Munich, Bochum, Karlsruhe, and Hanover.

What's striking about the frothy, 20-year spread of these centers is their fealty to the original Berkman template: faculty affiliates from across the host institution, visiting fellows, frequent talks, and public-facing reports and projects. The internet and society centers are, in effect, an idea-sharing technology, invented in Cambridge and spread around the world in a near-perfect case
Scott Brennen

Seth Lewis

Shawn Walker

Shira Chess

Shreeharsh Kelkar

Sean Lawson

Stephanie Schulte

Steven Schrag

Tamara Shepherd

Ted Striphas

Tim Highfield

Thomas Streeter

Tim Jordan

Tom Boellstorff

Tony Liao

Torin Monahan

Valerie Belair-Gagnon

Whitney Phillips

Zachary McDowell

Zizi Papacharissi

ARCHIVES

Archives Select Month

LINKS FOR CONTRIBUTORS

$\log \operatorname{In}$ 
of institutional isomorphism. Together with scholarly societies like the Association of Internet Researchers, the Berkman-style institutes are designed for cross-disciplinary exchange. They are also, in practice and by mission, welcoming to lay intellectuals from the worlds of journalism, nonprofit advocacy, government and Silicon Valley. At Berkman and many of its siblings, fellows remain affiliated once their fellowships end. They join what is, in Berkman's case, a network that now numbers in the hundreds.

So an initiative to grapple with the internet's implications for law has spawned a form-the cross-disciplinary "internet \& society" center-with a much wider mandate. Since its constituents are scattered across dozens of academic disciplines and non-academic fields, each with their own argot, the centers have adopted a plain-English ecumenicism by necessity. The result is a Babel-toppling forum for idea exchange that, through podcasting and reporting, reaches far beyond the academy.

A much smaller, but highly visible entrant in the internet research enterprise is the self-styled "media lab." The oldest, largest, and most famous lab is MIT's, of course, but labs like it have sprung up all over the world since its 1980 founding. The labs, typically funded by corporations and government grants, tend to have an engineering and design focus, but the biggest employ humanists and social scientists too. Most labs at least gesture, in their missions and initiatives, at the social implications of new technology: MIT's 26 research groups include Ethan Zuckerman's Civic Media center, a Human Dynamics initiative, a Scalable Cooperation group, and on and on. NYU's venerable Interactive Telecommunications Program, whose roots go back to the early 1970s Alternative Media Center, has an eclectic faculty that includes media analysts like Clay Shirky. At MIT, dozens of affiliated faculty and other researchers staff the the Lab's Media Arts and Sciences doctoral and master's programs.

Another node in this cross-disciplinary formation is Microsoft Research, established in 1991 with the broadest of mandates. The organization employs over a thousand academics around the world, most of them computer scientists, physicists, and engineers. But Microsoft Research's outposts in New York and Cambridge host a number of social scientists who, with a remarkable degree of autonomy, study emergent media. 
Microsoft's Social Media Collective, housed in New York and Cambridge, is the nerve center, with a roster of high-profile (and often critical) researcher-affiliates. Founded by the Berkeley iSchool-trained danah boyd in 2009, the Collective's principal researchers include Tarleton Gillespie, Mary Gray, and Kate Crawford. It's an irony of recent history that a fading software monopolist's research arm has incubated a number of talented postdocs, many of whom have gone on to prominent posts in traditional university departments. In 2015 Microsoft's danah boyd launched a standalone "think/do tank," Data \& Society, with a \$1 million startup grant from the Redmond software company. The New York-based research center operates in the Berkman mold, with fellows, public-facing reports, and a talk/podcast series.

A distinct bundle of centers takes crisis-seized journalism as its research charge. Some, like Harvard's Nieman Foundation and Shorenstein Center, have been around for decades, but are newly invigorated by the profession's vertiginous state. Oxford's Reuters Institute was established in 2006, but like the others has ramped up its research and report program with an in-house team and a rotation of visiting fellows. Columbia's Tow Center, housed in the university's journalism school, got underway in 2010 with the news business's digital travails very much in mind. Like the others, Tow has its own research staff and also hosts visiting scholars. Nieman, Shorenstein, Reuters, and Tow are joined by the foundation-affiliated, D.C.-based Pew Research Center. Pew began life back in 1990 as the Times Mirror Center for the People \& the Press, and, a few years later, was brought under the financial umbrella of the Pew Charitable Trusts. The current Center has a sprawling remit, mostly centered on polling American public opinion, but retains a strong journalismresearch team, as well as linked group of internet researchers.

The crucial point is that most of these new or revived centers sit outside the department structure. Few are formally tethered to a department or school of communication or library science. Indeed, the institutes are strongest at those universitiesHarvard and Oxford, for example-that had shunned the academic study of media for decades. Many of these centers subsist on endowments, grants, or corporate sponsorship. For most, filling lecture halls, or handing out degrees, isn't the 
point. (Not all of them: Oxford's Institute does offer master's and doctoral degrees, for example.)

Departments, by design and tradition, focus on teaching and faculty members' research agendas. The new media-research centers-many of them, anyway-are in a different business altogether. Their core activities are talks, fellowships, and reports: presentations by visitors, often streamed and/or podcasted, are attended by the institutes' fellows, alongside their much smaller standing faculty and staff. Public-facing reports, often grant-funded, are the centers' main "deliverable." Drafted by visiting fellows, often in collaboration with the centers' principals, these reports are part research paper, part press release, in the tradition of the American think tank. Polished landing pages, cover art, and vivid data visualizations are, by now, generic conventions. Bullet-pointed executive summaries distill, for the intended audience of journalists, academics, and the policy community, the reports' key takeaways.

The centers and institutes offer an institutionalized interdiscipline-a gathering place for idea exchange among disparate fields and traditions. A legal scholar critiques a library scientist, who in turn cites a communication researcher with a $\mathrm{PhD}$ in STS. What's been developed, without much forethought, is a trading zone in Peter Galison's sense: a space for thinkers, academic or otherwise, to listen, argue, and even collaborate. Berkman, Data \& Society and the like are substituting a crossroads for the more ponderous trappings of a discipline. Berkman doesn't hinge on Jonathan Zittrain, and most of the translational work, anyway, takes place in the organized fluidity of the talks and projects. In the Q\&A, in the hallway, on the listservs, a working creole-a shared bundle of concepts and vocabulary-is forming at these institutes. They are, like MIT's fabled Building 20, sites of serendipitous exchange. The reports and infographics and guidelines that the centers produce are quintessential boundary objects, plastic enough to adapt to the center's many constituent communities.

The new trading zone welcomes not just media and communication studies -in all its motley spread-but also law, library and information science, digital humanities scholars, and science and technology studies. It's an exciting development. The self-segregation-the enclosure, really-of communication 
research and library science on the university's professionalschool margins has had lots of bad consequences.

John Durham Peters, the brilliant media theorist, invoked geography in an early-career critique of communication: The would-be discipline, he wrote in the mid-1980s, was an "academic Taiwan-claiming to be all of China when, in fact, it was isolated on a small island." That claim was always chimerical, especially since the field's professional-school moorings left it isolated, in well-heeled, low-status, unread obscurity. A more fitting geographic metaphor for communication research, over its 60-odd year campaign for discipline status, is the Galápagos Islands.

The one thing the old system has going for it is a stable resource base in undergraduate students. What ultimately killed the midcentury Bureau of Applied Social Research and other interdisciplary experiments-like the University of Chicago's 1950s Committee on Communication-was their dependence on fickle-by-nature external funding. As the history of higher education in the U.S. has repeatedly confirmed, there's something like an iron law of interdisciplinary failure. The lesson from the 20th century is that academic units need studentsdegree-seeking undergraduates, especially-to endure.

Interdisciplinary structures that have no steady tuition funding eventually die off. They can subsist, for a stretch, on central administration dollars, foundation grants, and commercial contracts. None of these sources is reliable, though-not in combination and not over time. Client-based funding requires continual hustling, and gets undercut by cheaper non-university research-for-hire operations. Foundations are notoriously mercurial, and much prefer to start things than to sustain them. Universities face waves of cyclical cost-cutting that place softer targets-those without self-funding-on the chopping block. All it takes is two or three years of fiscal scrambling to send an interdisciplinary unit to the graveyard. As Stephen Turner has observed, intellectual projects, like armies, march on their stomachs.

So that's the big question mark hovering over the whole enterprise. The very conditions that swept the centers into existence-the dizzying experience of social whiplash-may fade with time, if we come to accept digital acceleration as the new normal. It's hard, at any rate, to sustain the elevated sense of 
urgency that these institutes need to survive.

Maybe things will turn out differently this time around. Perhaps the centers' spry, conference-room transience means they can survive budget belt-tightening. Some of the centers have healthy endowments that, to some extent, free them from the annual entreaty for funds. Some, like Oxford, offer degree programs and enjoy the stability that tuition affords. It's possible that the others will make themselves indispensable, as an extra-departmental overlay to the degree-granting disciplines that populate the social study of digital life. Wouldn't it be ironic if Berkman and the rest establish a lasting crossroads, where many pass and few tarry?

Note: Changes were made to the 13th, 21st, and 28th paragraphs to better reflect the Oxford Internet Institute's status as a degreegranting department.

\begin{tabular}{|c|c|c|c|c|c|}
\hline 377 & & 76 & 0 & 0 & 0 \\
\hline Y Tweet & Like & If Share & (D) Pin & in Share & $\nabla$ Email \\
\hline
\end{tabular}

POSTED IN: UNCATEGORIZED

AUTHOR

Jeff Pooley

Associate Professor of Media \& Communication at Muhlenberg College (jeffpooley.com)

CULTURE DIGITALLY IS SUPPORTED BY NSF AWARD NO. 1026523 | WP THEME BY MAXIMUS, MODIFICATIONS BY JOSH BRAUN, HECTOR POSTIGO, TARLETON GILLESPIE, AND SAM SRUAY | BACKGROUND IMAGES CC-BY-NC PAREERICA, CC-BY WEBTREATS | FLOSS FONTS INCLUDE DELICIOUS | POSTS COPYRIGHT BY THEIR RESPECTIVE AUTHORS UNLESS OTHERWISE NOTED 